\title{
Shatavari (Asparagus Racemosus) as green corrosion inhibitor of aluminium in acidic medium
}

\author{
Sumayah Bashir ${ }^{1}$, Garima Singh ${ }^{1}$, Ashish Kumar $^{2 *}$ \\ ${ }^{1}$ Department of Chemistry, School of Physical Sciences, Lovely Professional University, Punjab, India \\ ${ }^{2}$ Department of Chemistry, School of Civil Engineering, Lovely Professional University, Punjab, India
}

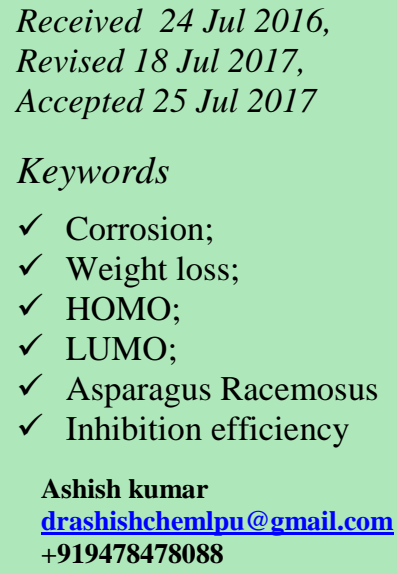

Received 24 Jul 2016,

Revised 18 Jul 2017,

Accepted 25 Jul 2017

Keywords

$\checkmark$ Corrosion;

$\checkmark$ Weight loss;

$\checkmark$ HOMO;

$\checkmark$ LUMO;

$\checkmark$ Asparagus Racemosus

$\checkmark$ Inhibition efficiency

Ashish kumar drashishchemlpu@gmail.com $\mathbf{+ 9 1 9 4 7 8 4 7 8 0 8 8}$

\begin{abstract}
Plant extracts containing heteroatoms can be used as corrosion inhibitors as they are non-polluting, cheap and eco-friendly. The present work focuses on Asparagus Racemosus (Shatavari) as a corrosion inhibitor of Aluminium in acidic medium. The techniques that have been used include weight loss method, quantum chemical analysis and scanning electron microscopy. It was seen that at $4000 \mathrm{ppm}$ concentration of inhibitor the corrosion inhibition efficiency was $72.28 \%$. The inhibition efficiency increased with increase in concentration. The best description of adsorption isotherm was seen to follow Langmuir adsorption isotherm. In order to elucidate the reactivity and molecular structure of inhibitor, quantum chemical parameters were utilized. The surface properties of the metal specimen were determined by SEM.
\end{abstract}

\section{Introduction}

Aluminium plays a pivotal role in automobiles, packaging, utensils, pipelines etc. In relation to corrosion, one of the most effected sectors is petroleum industry, metal industry, shipping segment, leading to major economical and resource loss [1]. Aluminium has a protective oxide layer over its surface which acts as an added advantage against corrosion. This aluminium oxide layer is, however, amphoteric in nature and thus, in highly acidic or basic medium it gets dissolved. This breakdown of protective oxide layer exposes bare metal surface for corrosion, therefore making it necessary to investigate methods for mitigation of corrosion in aluminium.

Aluminium metal (in the bare, protective oxide layer free form) once exposed to the electrolyte undergoes corrosion. The reaction corresponding to the presence of chloride ions in the medium is:

$$
[\mathrm{Al}(\mathrm{OH})]^{+2}+\mathrm{Cl}^{-} \leftrightarrow\left[\mathrm{Al}(\mathrm{OH}) \mathrm{Cl}^{+}\right.
$$

Since the order of the reaction obtained is three, thus a soluble complex $[\mathrm{Al}(\mathrm{OH}) \mathrm{Cl}] \mathrm{Cl}$ will be formed:

$$
[\mathrm{Al}(\mathrm{OH})]^{+2}+2 \mathrm{Cl}^{-} \leftrightarrow[\mathrm{Al}(\mathrm{OH}) \mathrm{Cl}] \mathrm{Cl}
$$

Formation of this soluble complex ion leads to an increase in the deliquescence of metal which depends on the concentration of chloride ions. Thus, we can say, with the increasing concentration of $\mathrm{HCl}$, an increase in the corrosion rate is observed [2-3].

Large numbers of organic compounds have been used as corrosion inhibitors. Mostly, the compounds containing heteroatoms like $\mathrm{O}, \mathrm{N}, \mathrm{S}$ in their structure are thought to be efficient prevent the corrosion of $\mathrm{Al}$ in many inhibitors have been used such as imidazoline derivatives [4], capparis decidua [5], delonix regia extract [6], gongronima latifolium extract [7], Bismarck brown eye [8], methyl orange [9], onion extract [10], hibiscus rosa- Sinesis [11] etc. These inhibitors have numerous N, O and S containing alkaloids which are get adsorbed on metal surface which basically hinder the release of $\mathrm{H}+$ and disintegration of metal ions. Steroidal Saponins - 
Shatavarin (I) and Sarsasapogenin (II) are the active constituents of Asparagus Racemosus. The structure of these constituents can be given below:

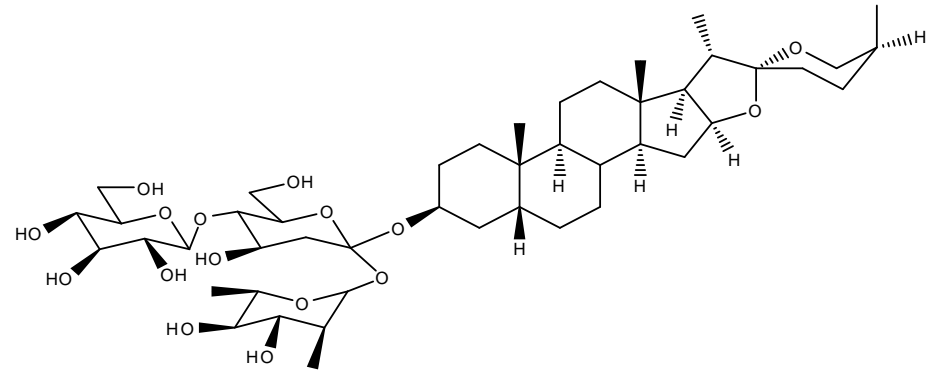

Shatavarin (I)

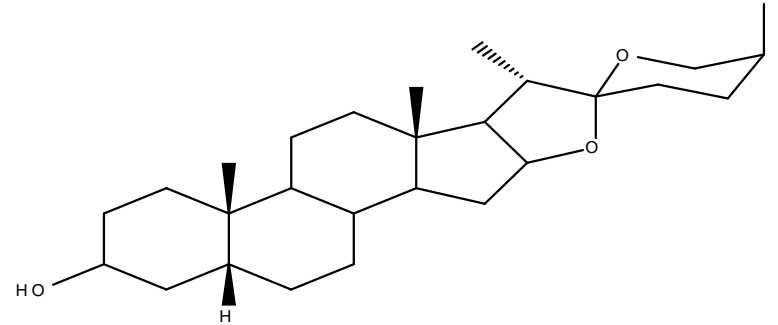

Sarsasapogenin (II)

Inhibition efficiency of corrosion inhibitors increases with increase in concentration of active components as well as it is directly proportional to the number of electron withdrawing or electron donating groups present in the inhibitor [12]. Presence of heteroatom's, polar functional groups and $\pi$-electrons as active centers in a particular compound makes it an effective corrosion inhibitor [13-15] because these hetero atoms or $\pi$-electrons facilitate electronic interactions between metal and inhibitor which in turn helps in the adsorption of inhibitor onto the metal surface [16]. Increase in environmental awareness has raised the demand of green, non- toxic, cheap and environment friendly corrosion inhibitors [17-19]

\section{Experimental}

\subsection{Materials}

The Aluminium coupons having chemical composition $0.35 \% \mathrm{Fe}, 0.25 \% \mathrm{Si}, 0.05 \% \mathrm{Cu}, 0.05 \% \mathrm{Zn}, 0.03 \% \mathrm{Mg}$, $0.03 \% \mathrm{Mn}, 0.03 \%$ Ti and remainder $99.60 \%$ being has been utilized.

\subsection{Weight loss method}

The dimensions of aluminium coupons used were $2 \times 2.5 \times 0.1 \mathrm{~cm}$. Before performing the experiment the coupons were abraded with emery papers of grade nos. 100, 220 and 400, which were then washed with distilled water and acetone. The weight loss of polished and dried aluminium coupons was ascertained by weighing the metal coupon before and after immersing in $100 \mathrm{cc}$ of $1 \mathrm{M} \mathrm{HCl}$ in absence (blank) and presence of inhibitor. The percentage inhibition efficiency was calculated using following formula:

$$
\eta \%=W o-W i / W o \times 100
$$

Where, Wo $=$ weight loss in the Blank Solution, $\mathrm{Wi}=$ weight loss in the presence of inhibitor at the said concentration and $\eta \%$ is the inhibition efficiency.

\subsection{Quantum chemical analysis}

Quantum substance examination was performed utilizing the MNDO and AM1 technique for the quantum chemical package MOPAC 6.0 of Hyperchem 7.5. The algorithm utilized for calculation was Polak-Rieberre, which is quick and precise. The accompanying parameters were (EHOMO), (ELUMO), energy band gap, $\Delta \mathrm{E}=$ EHOMO-ELUMO, binding energy, heat of formations and the dipole minute $(\mu)$.

\subsection{SEM analysis}

For SEM analysis, the aluminium coupons were immersed in $100 \mathrm{~mL}$ of $1 \mathrm{M} \mathrm{HCl}$ in the presence and absence of optimum concentration of the two inhibitors, separately, for $1 \mathrm{hr}$. Then they were removed, rinsed quickly (with sodium bicarbonate, water and acetone) and dried. The surface morphology of the metal coupons was determined and recorded using Scanning electron microscope 


\section{Results and discussion}

\subsection{Weight loss studies}

The weight loss experiments were studied separately with respect to concentration of inhibitor, time of immersion and temperature. As the temperature was increased, the corrosion inhibition efficiency was also seen to increase. Table 1 summarizes the effect of inhibitor concentration of the corrosion inhibition efficiency. The maximum efficiency of $74.4 \%$ is seen that the inhibitor concentration of 6000ppm. All these results are observed at $298 \mathrm{~K}$. the increase in inhibition efficiency due to increase in concentration is because of increased adsorption coverage of aluminium on addition of inhibitor.

Table 1: Inhibition efficiency ( $\mathrm{\eta} \%$ ) of Asparagus Racemosus on Aluminium at $298 \mathrm{~K}$

\begin{tabular}{|l|l|l|l|l|l|l|}
\hline S. No. & $\begin{array}{l}\text { Acid(M) } \\
\text { Inhibitor }(\mathrm{ppm})\end{array}$ & Wo $(\mathrm{g})$ & Wi $(\mathrm{g})$ & Wo-Wi(g) & $\Theta$ & $\eta \%$ \\
\hline 1 & $1 \mathrm{M}$ & 0.3778 & 0.1873 & 0.1905 & NA & NA \\
\hline 2 & 1000 & 0.3736 & 0.2728 & 0.1008 & 0.470866 & 47.08661 \\
\hline 3 & 2000 & 0.3733 & 0.3052 & 0.0681 & 0.64252 & 64.25197 \\
\hline 4 & 3000 & 0.3727 & 0.3174 & 0.0553 & 0.709711 & 70.97113 \\
\hline 5 & 4000 & 0.3778 & 0.325 & 0.0528 & 0.722835 & 72.28346 \\
\hline 6 & 5000 & 0.3771 & 0.328 & 0.0491 & 0.742257 & 74.22572 \\
\hline 7 & 6000 & 0.3712 & 0.3225 & 0.0487 & 0.744357 & 74.4357 \\
\hline
\end{tabular}

It was seen that increase in temperature leads to decrease in inhibition efficiency. The inhibition efficiency was seen at the temperatures varying from 288 to $303 \mathrm{~K}$ at the inhibitor concentration of $4000 \mathrm{ppm}$. As the temperature increase, the corrosion rate also increases leading to the decrease in inhibition. The corrosion of metal in acidic medium is typically joined by the evolution of $\mathrm{H}_{2}$ gas; increase in temperature fastens the corrosion rate resulting in higher dissolution of metal [20]. Table 2 gives the estimations of inhibition efficiency and surface coverage at various temperatures.

Table 2: Inhibition efficiency and surface coverage of Asparagus Racemosus on $\mathrm{Al}$ at different temperatures

\begin{tabular}{|c|c|c|c|c|c|c|c|}
\hline S. No & $\begin{array}{l}\text { Temp } \\
(\mathrm{K})\end{array}$ & $\begin{array}{l}\text { Inhibitor Concentration } \\
(\mathrm{ppm})\end{array}$ & $\begin{array}{l}\text { Initial Wt. } \\
(\mathrm{g})\end{array}$ & $\begin{array}{l}\text { Final } \\
\text { Wt. }(g)\end{array}$ & $\begin{array}{l}\text { Weight Loss } \\
\text { (g) }\end{array}$ & $\theta$ & $\eta(\%)$ \\
\hline \multirow[t]{2}{*}{1} & \multirow[t]{2}{*}{303} & Blank (1 M) & 0.3786 & 0.0228 & 0.3558 & NA & NA \\
\hline & & Shatavari (4000) & 0.3714 & 0.256 & 0.1154 & 0.67566 & 67.56605 \\
\hline \multirow[t]{2}{*}{2} & \multirow[t]{2}{*}{298} & Blank (1M) & 0.3795 & 0.054 & 0.3255 & NA & NA \\
\hline & & Shatavari (4000) & 0.3715 & 0.2812 & 0.0903 & 0.722581 & 72.25806 \\
\hline \multirow[t]{2}{*}{3} & \multirow[t]{2}{*}{293} & Blank (1M) & 0.3709 & 0.1196 & 0.2513 & NA & NA \\
\hline & & Shatavari (4000) & 0.3718 & 0.3128 & 0.059 & 0.765221 & 76.52209 \\
\hline \multirow[t]{2}{*}{4} & \multirow[t]{2}{*}{288} & Blank (1M) & 0.3769 & 0.1672 & 0.2097 & NA & NA \\
\hline & & Shatavari (4000) & 0.3734 & 0.3326 & 0.0408 & 0.805436 & 80.54363 \\
\hline
\end{tabular}

\subsection{Adsorption study}

The type of the adsorption isotherm can comprehend the interaction of inhibitor particles and the metal surface. The estimations of surface coverage relating to concentrations of inhibitor are utilized to get the best straight adsorption fit isotherm. The most generally utilized adsorption isotherm is Langmuir and Freundlich. The below equations are their representations separately: 
Langmuir isotherm, $\frac{\theta}{1-\theta}=\mathrm{K}_{\text {ads }} \mathrm{C}$

Freundlich isotherm, $\theta=\mathrm{K}_{\mathrm{ads}} \mathrm{C}$

$\mathrm{K}_{\mathrm{ads}}$ stands for the adsorption equilibrium constant, $\Theta$ is the surface coverage and $\mathrm{C}$ defines the concentration of inhibitor in ppm. Figure 1 gives the Langmuir adsorption isotherm. Slope of C/ $\Theta$ vs. $\mathrm{C}$ gives a straight line with slope almost equal to 1 suggesting the adsorption of inhibitor on aluminium surface follows Langmuir adsorption isotherm [21].

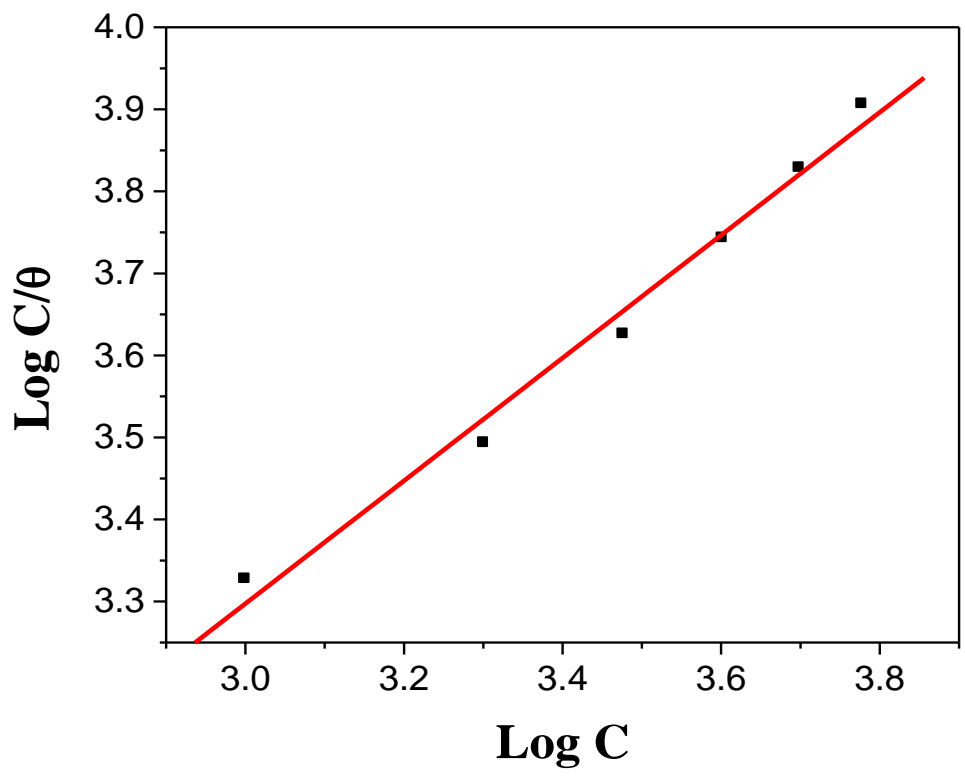

Figure 1: Langmuir adsorption isotherm of Asparagus Racemosus as corrosion inhibitor of $\mathrm{Al}$ in $\mathrm{HCl}$ at $298 \mathrm{~K}$ Thermodynamic activation parameters were elucidated based on the temperature dependence of corrosion rate by Arrhenius equation:

$$
C_{R}=A \exp \left(\frac{-E_{a}}{R T}\right)
$$

Where Ea is the apparent effective activation energy, $\mathrm{R}$ is the general gas constant, $\mathrm{CR}$ is the corrosion rate. The enthalpy of activation was calculated by using Eyring equation:

$$
\ln \frac{\mathrm{C}_{\mathrm{R}}}{\mathrm{T}}=\left(-\frac{\Delta \mathrm{H}}{\mathrm{R}}\right) \cdot \frac{1}{\mathrm{~T}}+\left(\frac{\ln \mathrm{R}}{\mathrm{Nh}}+\frac{\Delta \mathrm{S}}{\mathrm{R}}\right)
$$

Where, $\mathrm{h}$ is the planks constant, $\mathrm{N}$ is the Avogadro's number, $\Delta \mathrm{H}$ is the enthalpy of activation and $\Delta \mathrm{S}$ is the entropy of activation. A plot of $\log C_{R}$ versus $1000 / T$ gave a straight line as appeared in figure 2 .

The estimations of activation energy acquired from the slope of lines are recorded in table 3. Fig. 3 demonstrated the plot of $\log \mathrm{CR} / \mathrm{T}$ versus $1000 / \mathrm{T}$. Straight lines were acquired with a slant of $(-\Delta H / R)$ and intercept of $[(\ln (\mathrm{R} / \mathrm{Nh})+(\Delta \mathrm{S} / \mathrm{R})]$ from which estimations of $\Delta \mathrm{H}$ and $\Delta \mathrm{S}$ are ascertained.

Examination of table 3 demonstrated that values of Ea measured for the solution containing the inhibitor are greater than in blank $\mathrm{HCl}$. Elevation in Ea determines either physical adsorption or because of decline in the adsorption of inhibitor particles on aluminum as a result of increase temperature [20]. The endothermic nature of reaction was demonstrated by the positive value of $\Delta \mathrm{H}$. As far the estimations of $\Delta \mathrm{S}$ are concerned it demonstrates that the ordering of inhibitor atoms on the surface of metal [22]. 


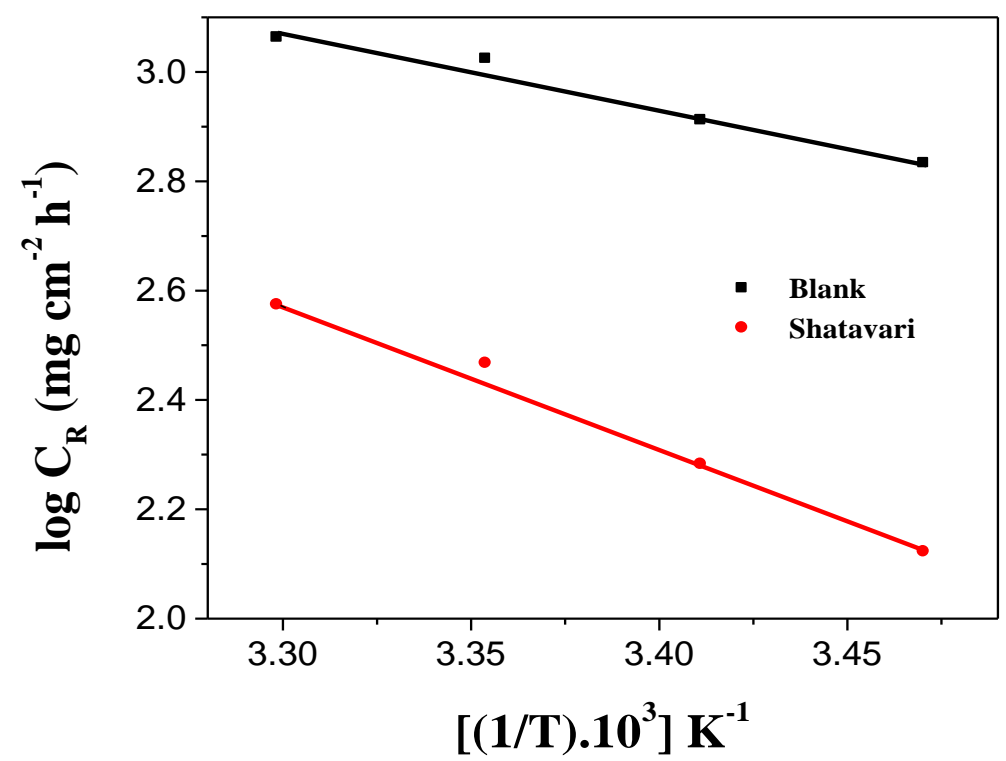

Figure 2: Arrhenius plot of $\log \mathrm{C}_{\mathrm{R}}$ vs. 1000/T for aluminium in $1 \mathrm{M} \mathrm{HCl}$ in presence (optimum concentration of 4000ppm) and absence of inhibitor.

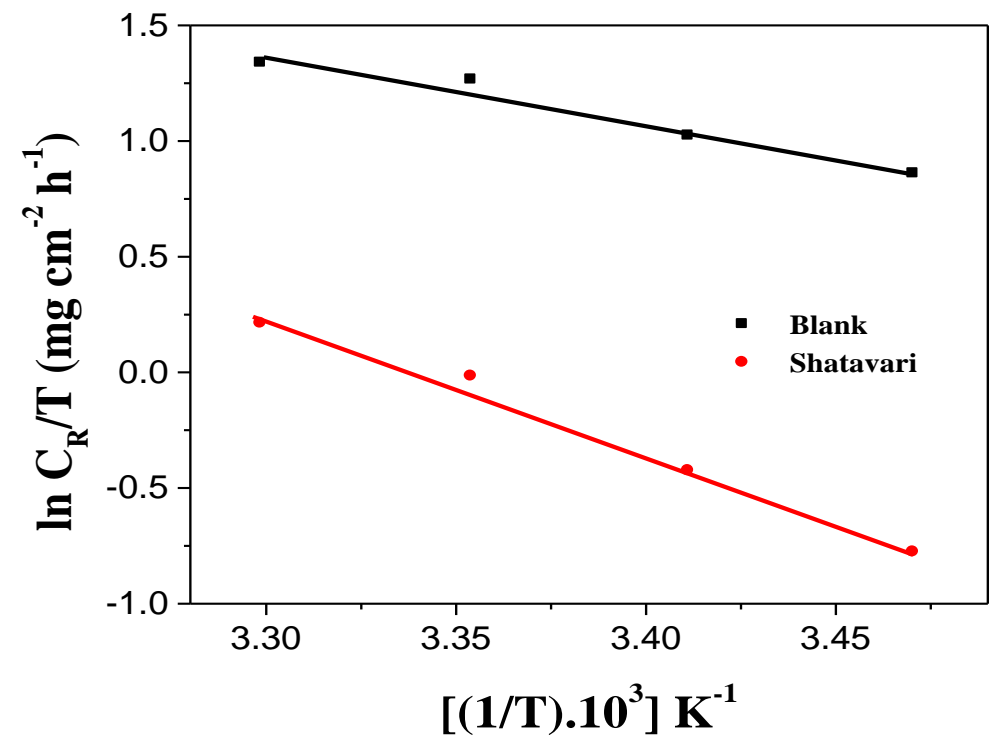

Figure 3: Arrhenius plot of $\log \mathrm{C}_{\mathrm{R}} / \mathrm{T}$ vs. $1000 / \mathrm{T}$ for aluminium in $1 \mathrm{M} \mathrm{HCl}$ in presence (optimum concentration of $4000 \mathrm{ppm}$ ) and absence of inhibitor

Table 3: Thermodynamic parameters in presence and absence of inhibitor

\begin{tabular}{|l|l|l|l|l|}
\hline S.No. & Inhibitor & $\Delta$ Hads $\left(\mathrm{kJ} \mathrm{mol}^{-1}\right)$ & $\Delta$ Sads $\left(\mathrm{J} \mathrm{K}^{-1} \mathrm{~mol}-1\right)$ & $\mathrm{Ea}\left(\mathrm{kJ} \mathrm{mol}^{-1}\right)$ \\
\hline 1 & Blank & 24.36526 & -105.78 & 26.82782654 \\
\hline 2 & Shatavari & 49.06025 & -33.6424 & 51.52534206 \\
\hline
\end{tabular}




\subsection{Mechanism of adsorption}

The interaction of metal and the inhibitor is based on the mechanism of inhibition. Mechanism of adsorptions gives us an idea about the metal electron interaction with the protective inhibitor molecules. Aluminium is considered to be positively charged in $\mathrm{HCl}$ with respect to the potential zero charge. Hence, inhibitor exists as neutral molecule in acidic solution. Fig 4 elucidates the donor acceptor interaction between unshared electron of the heteroatom and the vacant $\mathrm{p}$ orbital of aluminium metal.

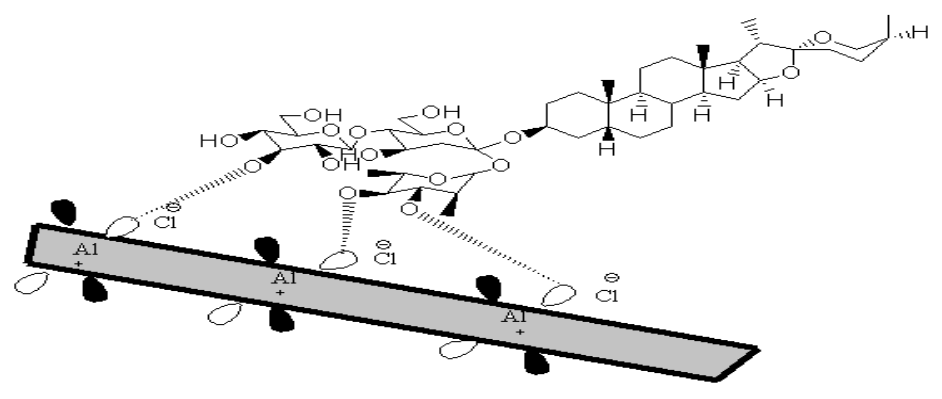

Figure 4: Adsorption behavior of inhibitor on the surface of Aluminium.

\subsection{Quantum chemical study}

These estimations were performed so as to explore the process of adsorption and mechanism of inhibition examined for inhibitor molecule. The different optimized structures of inhibitor are given in Figure 5.

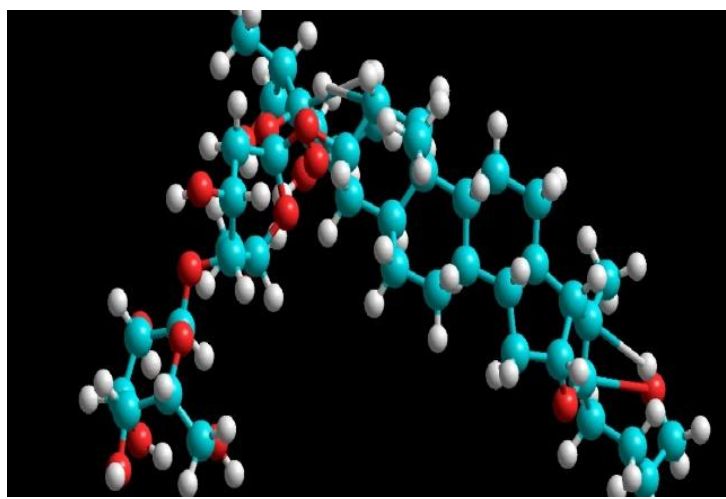

Figure 5. (a)

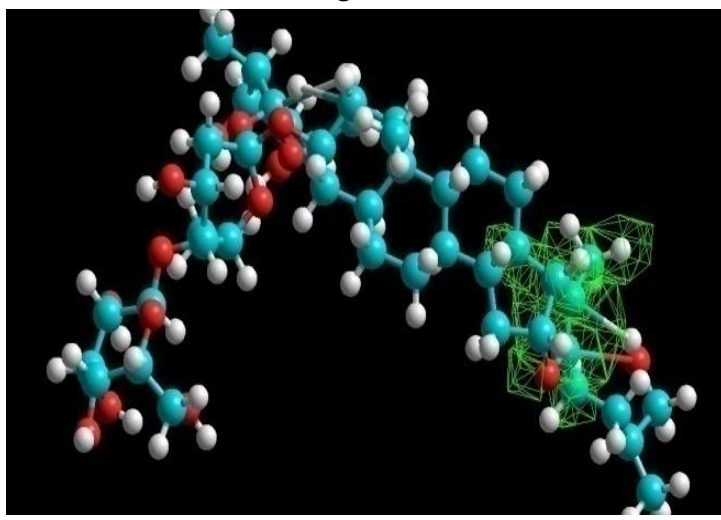

(c)

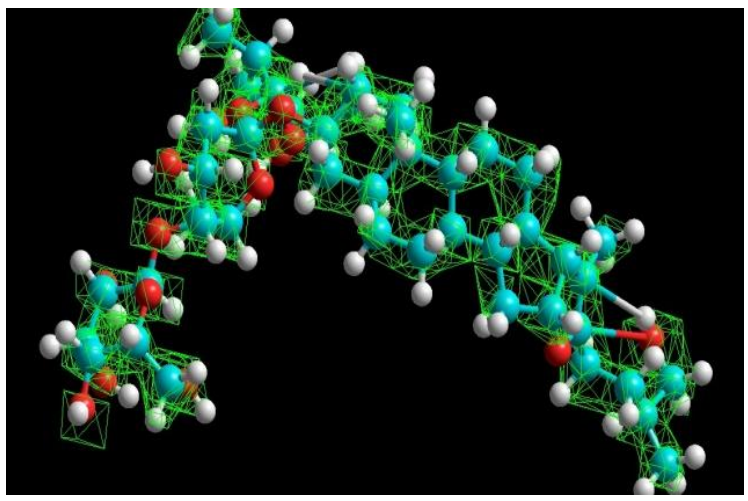

(b)

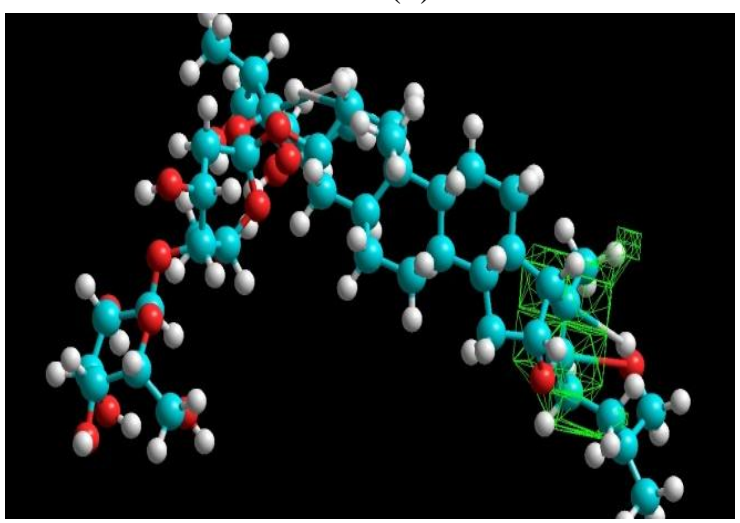

(d)

Figure 5: Quantum chemical structures of Asparagus Racemosus

(a) Geometry optimization.(b) Total charge density. (c) HOMO (d) LUMO. 
Keeping in mind the end goal to develop a molecular structure and reactivity of an inhibitor, it might be essential to concentrate on the properties that specifically impact the metal inhibitor interaction. Some of these parameters include, energies of sub-atomic orbital, $\mathrm{E}_{\mathrm{HOMO}}, \mathrm{E}_{\mathrm{LUMO}}, \Delta \mathrm{E}\left(\mathrm{E}_{\mathrm{LUMO}}-\mathrm{E}_{\mathrm{HOMO}}\right)$, and dipole minute. The estimation of these computed quantum compound parameters are given in table 4 . As $\mathrm{E}_{\text {НОмо indicates with }}$

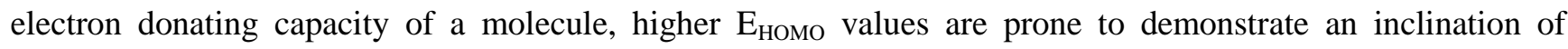
molecule for donation of electrons to the acceptor molecule. Larger values of $\mathrm{E}_{\text {номо }}$ encourage adsorption by impacting the transport process through adsorbed layer. In this way, the energy of $\mathrm{E}_{\mathrm{Lumo}}$ demonstrates the capacity of an atom to accept electrons. The lower $\mathrm{E}_{\mathrm{LUMO}}$ values, the more likely is that the atom would accept electrons. Lower values of $\Delta \mathrm{E}\left(\mathrm{E}_{\mathrm{LUMO}}-\mathrm{E}_{\mathrm{HOMO}}\right)$ propose higher corrosion inhibition efficiency because the energy required for removing the electron will be low [23]. Higher dipole minute proposes more adsorption in this way higher inhibition efficiency because of more polarization [20].

Table 4: Quantum chemical parameters of Asparagus Racemosus

\begin{tabular}{|c|c|}
\hline Dipole Moment & 8.022 \\
\hline $\mathrm{E}_{\text {HOMO }}$ & $-8.834484 \mathrm{eV}$ \\
\hline $\mathrm{E}_{\mathrm{LUMO}}$ & $0.958921 \mathrm{eV}$ \\
\hline$\Delta \mathrm{E}\left(\mathrm{E}_{\mathrm{LUMO}}-\mathrm{E}_{\mathrm{HOMO}}\right)$ & $9.793405 \mathrm{eV}$ \\
\hline
\end{tabular}

\subsection{SEM analysis}

The morphology of the metal specimen was revealed by SEM. The micrographs in fig $5(\mathrm{a}, \mathrm{b}, \mathrm{c})$ show the micrograph of polished aluminium coupon without immersion in either of the solutions, specimen in blank $\mathrm{HCl}$ and inhibitor solution respectively.

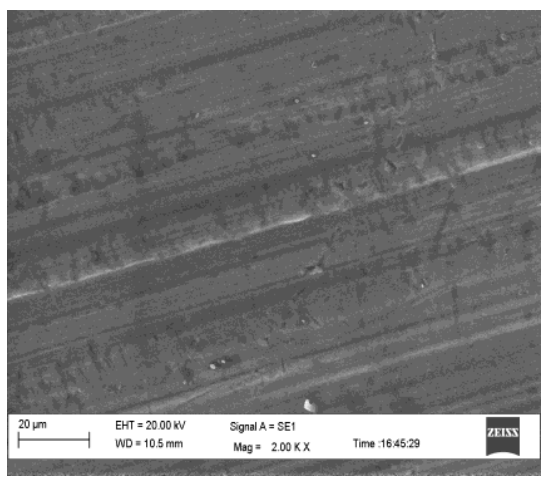

(a)

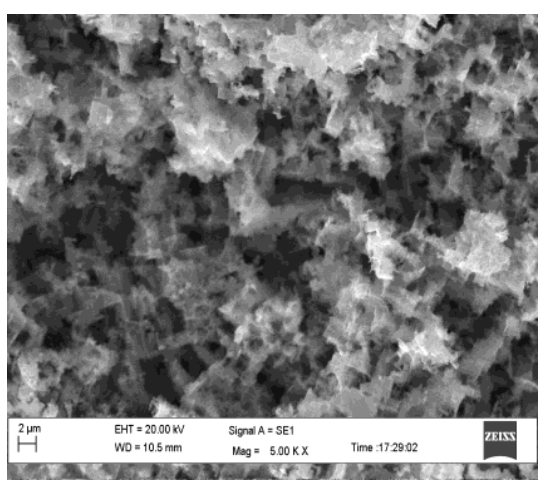

(b)

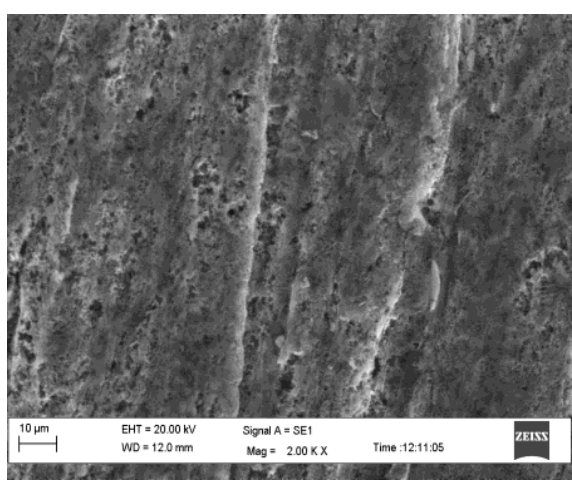

(c)

Figure 6: SEM micrographs of aluminium in $1 \mathrm{M} \mathrm{HCl}$ after $1 \mathrm{hr}$ immersion time.(a) polished aluminium coupon (b) Blank $1 \mathrm{M} \mathrm{HCl}$ (c) inhibitor (4000ppm).

It is clear from the figure that (a) has large number of pits and cavities and also the surface is rough whereas in case of (b) the pits are less and surface is smooth which is an evidence that inhibitor has formed a protective layer on the surface of metal through adsorption [24-27].

\section{Conclusion}

The results demonstrate that Asparagus Racemosus is an effective corrosion inhibitor of aluminium in acidic medium. The positive value of $\Delta \mathrm{H}$ suggests that the reaction is endothermic and the rate of corrosion is slow. The adsorption of inhibitor on the surface of aluminium obeys Langmuir adsorption isotherm. The addition of inhibitor leads to increase in activation energy showing that inhibitor is being physically adsorbed on the surface of metal. Quantum compound approach is adequate to estimate the effectiveness of inhibitor utilizing hypothetical approach. 
Acknowledgments-The authors are pleased to acknowledge Lovely Professional University (LPU) for providing the facilities for the research.

\section{References}

1. Hurlen T., Lian H., Odegard O., Valand T., Electrochim. Acta, 49 (1984) 537.

2. El Ouali I., Hammouti B., Aouniti A., Ramli Y., Azougagh M., Essassi E.M., Bouachrine M., J. Mater. Environ. Sci. 1 (2010) 1.

3. Nguyen T.H., and Foley R.T., J. Electrochem. Soc. 129 (1982) 129.

4. Putilova I.N., Balizin S.A., Baranik V.P., Met. Corr. Inhib. Per. Press London. (1960) 305.

5. JainT., Choudhary R. and Mathur S.P., Mat. and Corr. 57 (2006) 422.

6. Okafor P.C., Ikpi M.E., Uwah I.E., Ebenso E.E., Elcpe U.J., Umoren S.A., Corr. Sci. 50 (2008) 2310.

7. Choudhary R., Jain T. Mathur S.P., Bull. of Electrochem. 20 (2004) 67.

8. Sharma P., Upadhyay R.K., Chaturvedi A., Parashar R., J.T.R. Chem. 15(1) (2008) 21.

9. Talati J.D., and Gandhi D.K., Ind. J. Tec., 29 (1991) 227.

10. Dubey R.S. and Upadhyay S.N., J. Electrochem. Soc. India. 74 (1944) 143.

11. Rajendran S., Jeyasundari J., Usha.., Selvi J.A., Narayanasamy B., Regis A.A. P., Rengan P., Portug. Electrochim. Acta. 27 (2009) 2.

12. Verma C., Olasunkanmi L.O., Ebenso E.E., Quraishi M.A., and Obot I.B., J. Phys. Chem. C. 120 (2016) 11598.

13. Quraishi M.A., Ansari K.R., Yadav D.K., and Ebenso E.E., Int. J. Electrochem. Sci. 7 (2012) 12301.

14. Bousskri A., Anejjar A., Messali M., Salghi R., Benali O., Karzazi Y., Jodeh S., Zougagh M., Ebenso E.E., Hammouti B., J. Mol. Liq. 211(2015) 1000.

15. Belghiti M. E., Tighadouini S., Karzazi Y., Dafali A., Solmaz R., Hammouti B., Radi S., J. Mater. Environ. Sci. 7 (2016) 319.

16. Geethamani P., Kasthuri P.K., Cog. Chem. 1 (2015) 1091558.

17. Majidi L., Znini M., Ansari A., Hammouti B., Jama C., Costa J., Paolini J., Int. J. Electrochem. Sci. 8 (2013) 7381.

18. Elmouaden K., Chaouay A., Oukhrib R., Jbara O., Jodeh S., Salghi R., Hamed O., Hilali L. bazzi M., Hammouti B., Radi S., Int. J. Electrochem. Sci., 10 (2015) 7955.

19. Gerengi H., Ugras H.I., Solomon M.M., Umoren S.A., Kurtay M., and Atar N., J. Adh. Sci. Tech. 1 (2016) 1. 20. Yadav D.K., Maiti B., and Quraishi M.A., Corr. Sci. 52 (2010) 3586.

21. Hmamou D.B., Salghi R, Zarrouk A., Benali O., Fadel F., Zarrok H., and Hammouti B., International J. Ind. Chem. 3 (2012) 25.

22. Quraishi M.A., Danish J., Mat. Chem. Phys. 78 (2003) 687.

23. Belghiti M.E., Karzazi Y., Tighadouini S., Dafali A., Jama C., Warad I., Hammouti B., Radi S., J. Mater. Environ. Sci. 7 (2016) 956.

24. Salim R., Ech Chihbi E., Oudda H., ELAoufir Y., El-Hajjaji F., Elaatiaoui A., Oussaid A., Hammouti B., Elmsellem H. and Taleb M., Der Pharma Chemica 8(3) (2016) 200-213.

25. Kumar A., and Bashir S., Russian J. App. Chem., 89 (2016) 1158.

26. Benabdellah M., Tounsi A., Khaled K.F., Hammouti B., Arabian Journal of Chemistry 4 (2011) 17-24

27. Pandian B.R., and Sethuraman M.G., Mat. Lett. 62 (2008) 2977.

\section{(2017) ; http://www.jmaterenvironsci.com}

